University for Business and Technology in Kosovo

UBT Knowledge Center

Oct 28th, 9:00 AM - Oct 30th, 5:00 PM

\title{
Strengthening the reinforced concrete column with CF sheet
}

Florim Istrefi

University of Zagreb, f_ing@hotmail.com

Follow this and additional works at: https://knowledgecenter.ubt-uni.net/conference

Part of the Engineering Commons

\section{Recommended Citation}

Istrefi, Florim, "Strengthening the reinforced concrete column with CF sheet" (2016). UBT International Conference. 11.

https://knowledgecenter.ubt-uni.net/conference/2016/all-events/11

This Event is brought to you for free and open access by the Publication and Journals at UBT Knowledge Center. It has been accepted for inclusion in UBT International Conference by an authorized administrator of UBT Knowledge Center. For more information, please contact knowledge.center@ubt-uni.net. 
Book of Proceedings

International Conference on Civil Engineering, Infrastructure and Environment

\title{
Strengthening the reinforced concrete column with $\mathrm{CF}$ sheet
}

\author{
Florim Istrefi \\ University of Zagreb, Faculty of Civil Engineering \\ f_ing@hotmail.com
}

\begin{abstract}
Fiber reinforced polymer (FRP) composites (the combination of two or more materials). The strengthening of concrete members means using constructional measures to restore or improve their load-carrying capacity, serviceability, durability or fatigue strength.

The effects of strengthening measures can generally be described in quantitative terms and therefore analyzed numerically for reinforced concrete columns designed according to the earlier editions of DIN 1045, ACI Committee 440, 2002, there are some strengthening assignments that fall midway between redesign and sprayed concrete. It is for these projects that wrapping with fiber-reinforced materials is to be recommended. This method has already been used frequently in Europe and elsewhere, often on the basis of design codes or guides covering the subsequent strengthening of reinforced concrete compression members by means of wrapping with fiber-reinforced materials.

This paper presents an example for strengthening the reinforced concrete column a wrapping of $\mathrm{CF}$ sheet externally.
\end{abstract}

Keywords: Composite, CF sheets, reinforced concrete columns, wrapping, strengthening.

\section{Introduction}

Strengthening of concrete structural members like beams, slabs, columns may be required on many cases such as deterioration of structure due to environmental effect, damage caused by accidents, upgraded loading requirements, revision in loading standard, bomb blasts and seismic retrofitting. The confinement of columns is achieved by means of internal lateral reinforcement (hoop or closed stirrups) or by external reinforcement (steel or FRP jackets). In the latter case, the confinement reinforcement can be provided either through external strengthening of existing columns, or as formwork that acts as structural reinforcement after construction of the columns. Confinement is generally applied to members in compression, with the aim of enhancing their load carrying capacity or, in cases of seismic upgrading, to increase their ductility.

\section{General}

The design of concrete member reinforced with fibre reinforced polymer (FRP) has many different design considerations than a steel reinforced concrete member. Confinement of reinforced concrete columns significantly enhances the performance under axial load, bending and shear, because of the increase in concrete compressive strength, the increase in ductility, the increase in shear strength and 
the higher resistance against buckling of the steel reinforcement in compression. The confinement of columns is achieved by means of internal lateral reinforcement (hoop or closed stirrups) or by external reinforcement (steel or FRP jackets).

A large number of investigations conducted in the laboratory and field applications in buildings and bridges established the viability of composites for improving the performance of axially loaded members.

Rehabilitation and strengthening of structures with inadequate bearing capacity has reached a level of extended design alternatives. Use of fiber reinforced polymer (FRP) materials is growing, as they tend to replace conventional steel as external reinforcement in upgrading of existing structures. FRP materials turn to be more advantageous than steel.

\section{Example-column strengthening with $\mathrm{CF}$ sheets}

A reinforced concrete column in a business and residential building needs to be strengthened, a wrapping of CF sheet is to be used for strengthening the column.

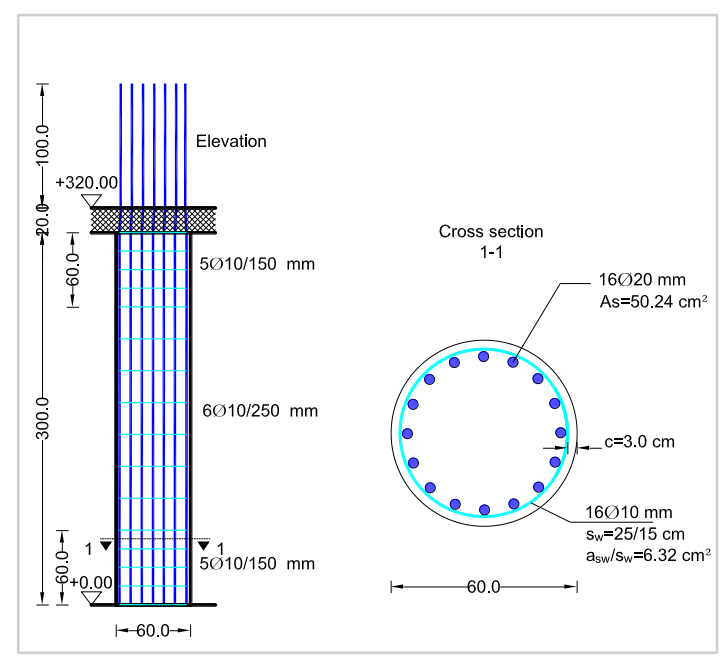

Fig. 1.1. Column system requiring strengthening, and layout of the existing reinforcement.

\subsection{Loading}

Three load cases will be investigated for ULS (ultimate limit state) design:

Load case 3 governs for designing the strengthening measures. The load combination for the ULS and the load combination for the SLS under a quasi-permanent load combination are required for the analyses.

$$
N_{E d}=7200.00 \mathrm{kN}
$$

and the loading for the SLS under a quasi-permanent load combination is 
Book of Proceedings International Conference on Civil Engineering, Infrastructure and Environment

$$
N_{E q p}=2900.0 \mathrm{kN}
$$

According to the project documents construction materials is: concrete class C 30/37, reinforcing steel is $\mathrm{B} 500 \mathrm{~B}$, also after the test on the member to, the result was concrete class is $\mathrm{C} 30 / 37$. In the figure 1.1 shows the structural system requiring strengthening, and layout of the existing reinforcement.

Table 1.1. Construction materials and characteristic values.

\begin{tabular}{|l|l|c|c|}
\hline \multicolumn{2}{|c|}{ Construction materials } & \multicolumn{2}{c|}{ characteristic values } \\
\hline Concrete class & C 30/37 & $f_{c m}=38 \mathrm{~N} / \mathrm{mm}^{2}$ & $E_{c m}=33 \mathrm{kN} / \mathrm{mm}^{2}$ \\
\hline Reinforcing steel & B $500 \mathrm{~B}$ & $f_{y k}=500 \mathrm{~N} / \mathrm{mm}^{2}$ & $E_{S}=200 \mathrm{kN} / \mathrm{mm}^{2}$ \\
\hline CF sheet & $t_{L, i}=0.15 \mathrm{~mm}$ & $f_{L u k}=3500 \mathrm{~N} / \mathrm{mm}^{2}$ & $E_{L}=230000 \mathrm{~N} / \mathrm{mm}^{2}$ \\
\hline
\end{tabular}

One layer of CF sheet has a nominal thickness $t_{L, i}=0.15 \mathrm{~mm}$. System coefficients, which for the system used here are listed in Table 1.2. according to DAfStb guideline [1] Annex RV K2.

Table 1.2. System coefficients for columns.

\begin{tabular}{|c|c|c|c|c|c|c|c|c|c|}
\hline$\left[\mathrm{k}_{0}\right]$ & {$\left[\mathrm{k}_{1}\right]$} & {$\left[\mathrm{k}_{2}\right]$} & {$\left[\mathrm{k}_{3}\right]$} & {$\left[\mathrm{k}_{4}\right]$} & {$\left[\mathrm{k}_{5}\right]$} & {$\left[\mathrm{k}_{6}\right]$} & {$\left[\mathrm{k}_{7}\right]$} & {$\left[\mathrm{k}_{8}\right]$} & {$\left[\mathrm{k}_{9}\right]$} \\
\hline $0.21 /\left(\mathrm{N} / \mathrm{mm}^{2}\right)$ & 2 & 0.25 & 0.7 & 1 & 1 & 0.75 & 0.39 & 0.89 & $0.44 * 10^{-2}$ \\
\hline
\end{tabular}

Table 1.3 Axial loads and bending moments for the relevant load combinations.

\begin{tabular}{|l|c|c|}
\hline Load combination & $\mathrm{N}$ & $\mathrm{M}$ \\
\hline---- & $\mathrm{kN}$ & $\mathrm{kNm}$ \\
\hline Load case 3; ULS & $N_{E d}=7200$ & 57.6 \\
\hline Load case 3; SLS, quasi-permanent & $N_{E q p}=2900$ & 23.20 \\
\hline
\end{tabular}

\subsection{Determining the cross-sectional values}

$\alpha_{s}, A_{c}, A_{i}, I_{c}, I_{i}$, as can be seen from the equation, $z_{s}^{j}$ and $A_{s}^{j}$ must be determined. This is carried out below according to Figure 1.2. We must determine the positions of the bars, or rather the radi to the centres of the reinforcing bars first of all. This depends on the concrete cover and the diameter of the links $\phi_{s w}$ and the bars $\phi_{s}$. 


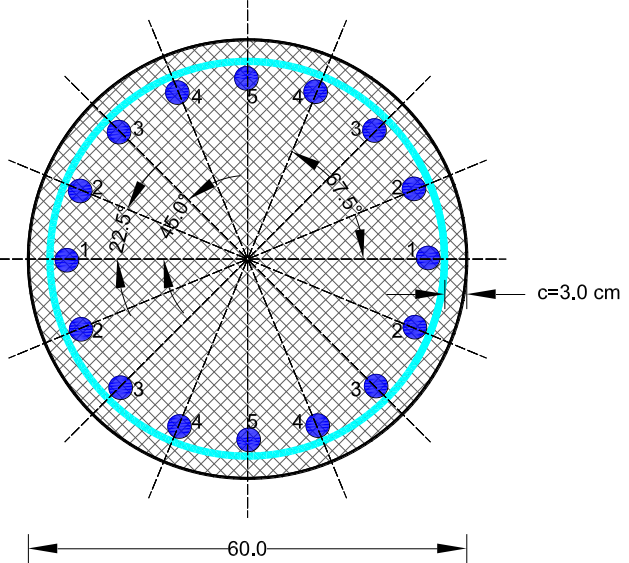

Fig. 1.2 Scheme for determining $A_{s}^{j} \& z_{S}^{j}$

\subsection{Boundary conditions}

The minimum column diameter complies with DAfStb guideline [1] part 1, RV 6.1.4.2, Eq. (RV 6.58): $D \geq 120 \mathrm{~mm}, \lambda \leq 40 ; f_{c m} \leq 58 \mathrm{~N} / \mathrm{mm}^{2}$, and minimum thickness

$t_{L} \geq 0.2$ is necessary in order to activate the multi-axial stress state by way of a sufficient confining effect.

$$
n_{L}=\frac{t_{L}}{t_{L, i}}
$$

A thickness $t_{L}=0.75 \mathrm{~mm}$ leads to a number of layers is $n_{L}=0.75 / 0.15=5.0$

The wrapping will consist of 6 layers. The column may therefore be strengthened in accordance with the method given in the DAfStb guideline [1].

\subsection{Verification of column load-carrying capacity}

A number of layers $n_{L}=6$ and the following fabric thickness are used in the analyses given below:

$$
t_{L}=n_{L} * t_{L, i}=6 * 0.15=0.9 \mathrm{~mm}
$$

\subsection{Creep of confined concrete}

$$
\varepsilon_{c c}(\Delta t)=\left[k_{7}\right] * \beta_{c}(\Delta t) * \beta\left(f_{c m}\right) * \beta_{0, k} * \frac{\sigma_{c p}}{E_{c m}}
$$

Compressive stress relevant to creep under a quasi-permanent load combination. 
Book of Proceedings International Conference on Civil Engineering, Infrastructure and Environment

$$
\sigma_{c p}=\left|\frac{N_{E q p}}{A_{i}}\right|+\left|\frac{M_{0 E q p}}{I_{i}}\right|=\left|\frac{N_{0, E q p}}{A_{i}}\right|+\left|\frac{M_{0, E q p}}{I_{i} * \frac{2}{D}}\right|=10.27 \quad \mathrm{~N} / \mathrm{mm}^{2}
$$

$\beta c(\Delta t)=1.0$, It is also important to check whether non-linear creep needs to be considered. To do this, the degree of utilization under a quasi-permanent load must be calculated. As this is $<0.45$, it is not necessary to consider non-linear creep and therefore $\beta 0, k=1$

$$
k_{\sigma}=\frac{\sigma_{c p}}{f_{c m}}=\frac{10.27}{38}=0.27 \leq 0.45
$$

The influence of the concrete compressive strength at the time of strengthening must be considered

$$
\beta\left(f_{c m}\right)=\frac{16.8}{\sqrt{f_{c m}}}=\frac{16.8}{\sqrt{38}}=2.73
$$

Now we can calculate the creep of the confined concrete

$$
\varepsilon_{c c}(\Delta t)=0.39 * 1 * 2.73 * 1 * \frac{10.27}{33000}=0.33 \mathrm{~mm} / \mathrm{m}
$$

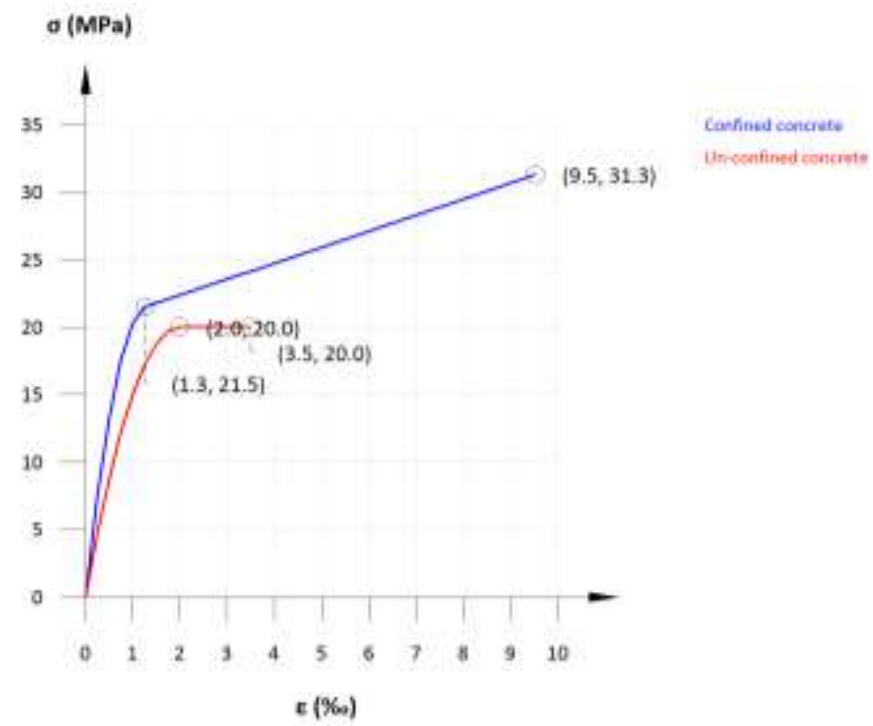

Fig. 1.3 Stress-strain diagram (un-confined and FRP-confined concrete)*

* Sika CarboDur softwar, CF Laminate-SikaWrap 301C - 60cm, the tensile strength of the concrete and confinement provided by any existing hoop steel is ignored by the software.

\subsection{Properties of the CF sheet}

The stiffness of the wrapping relative to the column diameter $\mathrm{D}$ is required for the next calculations, this relative stiffness is 
Strengthening the reinforced concrete column with CF sheet

$$
\begin{aligned}
& E_{j l}=\frac{2 * E_{l} * t_{l}}{D}=\frac{2 * 230000 * 0.9}{600}=690 \mathrm{~N} / \mathrm{mm}^{2} \\
& \varepsilon_{j u k}=\left[k_{2}\right] *\left[k_{3}\right] *\left[k_{4}\right] *\left[k_{5}\right] *\left[k_{6}\right] * \varepsilon_{L K}+\alpha_{k} * \vartheta * \varepsilon_{c c}(\Delta t)=2.3 \mathrm{~mm} / \mathrm{m}
\end{aligned}
$$

\subsection{Distribution of transverse compression}

$$
\begin{gathered}
t_{w, e f f}=\frac{A_{s w}}{2 * s_{w}}=\frac{6.32}{2}=0.316 \mathrm{~mm} \\
D_{c}=D-2 * c-2 * t_{w, e f f}=539.37 \mathrm{~mm} \\
p_{1}=\frac{2 * t_{L} * E_{L} * \varepsilon_{j u k}}{D}=E_{j L} * \varepsilon_{j u k}=1.59 \\
p_{2}=\frac{2 *\left(t_{L} * E_{L} * \varepsilon_{j u k}+t_{w, e f f} * f_{w y k}\right)-p_{1} * c}{D_{c}+c}=2.14 \\
\Delta p=p_{1}-\frac{2 * t_{L} * E_{L} * \varepsilon_{j u k}-\left(p_{1}+p_{1}\right) * c}{D_{c}}=0.032
\end{gathered}
$$

\subsection{Multi-axial stress state in concrete}

The characteristic compressive strength of the confined concrete is calculated using

$$
\begin{gathered}
f_{c c k}=34.62 \mathrm{~N} / \mathrm{mm}^{2} \\
\rho_{w y}=0.0031
\end{gathered}
$$

The stress block geometry factor $\alpha_{1}$ is also required:

$$
\alpha_{1}=1.17-0.2 * \frac{f_{c c k}}{f_{c k}^{*}}
$$

$f_{c k}^{*} \quad$ point at which projected straight part of curve intersects stress axis.

$$
\begin{gathered}
f_{c k}^{*}=f_{c k}+k_{1} *\left[\rho_{w y} * f_{w y k}-\Delta p\right] *\left(\frac{D_{c}-\frac{s_{w}}{2}}{D}\right)^{2}=31.44 \mathrm{~N} / \mathrm{mm}^{2} \\
\alpha_{1}=1.17-0.2 * \frac{34.62}{31.44}=0.949
\end{gathered}
$$

\subsection{Calculation of column load-carrying capacity}

The calculation to establish the load-carrying capacity of the column is carried out according to DAfStb guideline [1,2] part 1 section 6.1.4.2 (RV 5) and Eq. (RV 6.63).

To do this, the relative angle $\theta$ must be determined iteratively with the following equations. 
Book of Proceedings International Conference on Civil Engineering, Infrastructure and Environment

$$
N_{R d}=\frac{1}{\gamma_{L G}} * \theta * \alpha_{1} * f_{c c k} * A_{c} *\left(1-\frac{\sin (2 \pi \theta)}{2 \pi \theta}\right)+\frac{1}{\gamma_{s}} *\left(\theta_{c}-\theta_{t}\right) * f_{y k} * A_{s}
$$

The relative angle $\theta$ is estimated as $\theta=0.815$ for this example.

$$
\begin{gathered}
N_{R d}=7458.1 \mathrm{Kn} \\
M_{R d}=N_{R d} *\left(e_{t o t}+\left(\frac{l_{0}}{\pi}\right)^{2} * \xi_{1} * \xi_{2} * \emptyset_{b a l} * K_{\varphi}\right) \\
\xi_{1}=\frac{N_{b a l}}{N_{R k}}=\frac{0.8 * f_{c c k} * A_{c}}{N_{R d} * \gamma_{L G}} \leq 1 \Longrightarrow \quad \xi_{1}=0.783<1
\end{gathered}
$$

The strain coefficient $\rho_{\varepsilon}$ according to DAfStb guideline [1] part 1 Eq. (RV 6.99)

$$
\begin{gathered}
\rho_{\varepsilon}=\frac{\varepsilon_{j u}}{\varepsilon_{c 2}}=\frac{2.3}{2.0}=1.15 \\
\xi_{2}=1.092 \leq 1 \Rightarrow \xi_{2}=1
\end{gathered}
$$

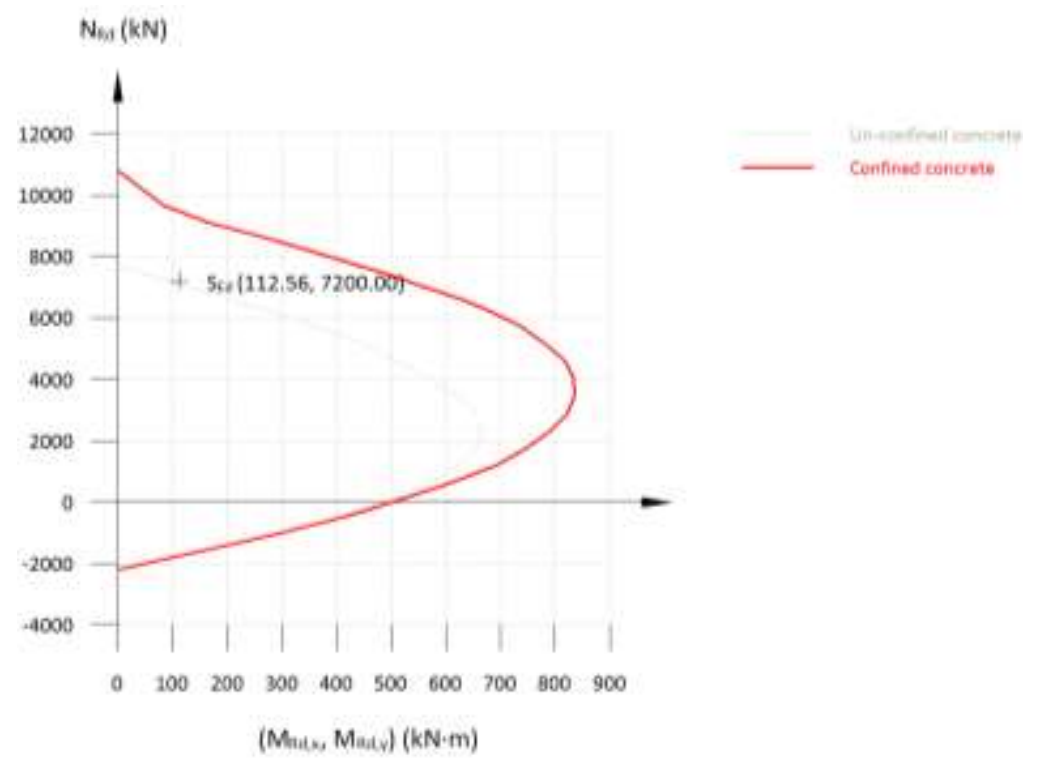

Fig. 1.3 Interaction diagrams $N_{R d}-M_{R d}$ (un-confined and FRP-confined concrete)* * Sika CarboDur softwar, CF Laminate-SikaWrap 301C - 60cm, the tensile strength of the concrete and confinement provided by any existing hoop steel is ignored by the software.

The maximum curvature $\emptyset_{\text {bal }}$, of the confined cross-section is determined according to DAfStb guideline [1,2] part 1 Eq. (RV 6.100), and after the calculate and using these variables $\varepsilon_{c u}, \varepsilon_{y k}, K_{\varphi}, \beta, \varphi_{e f}, K_{\varphi}$, it is possible to calculate the maximum acting moment

$$
M_{E d}=150.56 \mathrm{kNm}
$$


Strengthening the reinforced concrete column with CF sheet

$$
M_{R d}=150.48 \mathrm{kNm}
$$

$$
M_{E D} \cong M_{R d}
$$

As the acting axial load is less than the axial load resistance of the column, the column load-carrying capacity is satisfactory,

$$
N_{R d}=7458.1 k N \geq N_{E d}=7200 k N
$$

\subsection{Serviceability limit state}

In order to avoid unacceptable damage to the concrete microstructure at the serviceability limit state, specifies that the theoretical thickness of confining reinforcement necessary $t_{\mathrm{L}}$ must comply with the following condition:

$$
\begin{gathered}
t_{L} \leq \frac{D}{2 * E_{L^{*}} \varepsilon_{j u k}} * \frac{1}{\left[k_{0}\right]} *\left[\gamma_{L G} *\left[\gamma_{F} *\left(\left[k_{8}\right]-\left[k_{9}\right] * f_{c k}\right) *\left(\alpha_{c c} * f_{c k}+\frac{A_{s}}{A_{c}} *\left|\varepsilon_{c 2}\right| * E_{s}\right)-\frac{f_{y k}}{\gamma_{s}}+\frac{A_{s}}{A_{c}}\right]-\right. \\
\left.f_{c k}\right] \\
\gamma_{F}=\frac{N_{E d}}{G_{k}+Q_{k}}=\frac{7200}{2000+3000}=1.44
\end{gathered}
$$

Partial safety factor $\gamma_{F}$ for actions was calculated according to the contributions of the permanent and variable actions for the governing combination of forces and moments at the ultimate limit state:

$$
t_{L} \leq t_{L, \max }=2.16 \mathrm{~mm}
$$

As the thickness of confining reinforcement used is less than the maximum permissible Thickness, the design for serviceability is satisfactory.

$$
\Rightarrow t_{L}=0.9 \mathrm{~mm} \leq t_{L, \max }=2.16 \mathrm{~mm}
$$

\section{Conclusions}

- High-strength composites have been very effective in retrofitting columns to improve earthquake resistance. The composites are essentially used to confine the concrete, resulting in improvement of: compressive strength or axial force capacity, flexural and shear strength, flexural ductility and performance of lap splices.

- The stress-strain models for concrete confined with composite CF sheets indicate significant increases in compressive strength and strain at failure when compared with the unconfined concrete.

- The higher cost of FRP materials is soffset by reduced costs of labor, use of equipment, and downtime during installation

\section{References}


Book of Proceedings

International Conference on Civil Engineering, Infrastructure and Environment

1. DAfStb (German Committee for Reinforced Concrete) Guideline on the reinforcement of concrete parts with adhesive bonding - Part 1: Design and construction, 2012

2. EN 1991-1-1:2002 Actions on structures. General actions. Densities, self-weight, imposed loads for buildings

3. EN 1992-1-1:2013 Design of concrete structure-Part 1-1: General rules and rules for buildings, European Committee for Standardization, Brussels,

4. EN 1992-1-1:2013 Design of concrete structure-Part 1-1: General rules and rules for buildings, European Committee for Standardization, Brussels, National Annex

5. Z. Sorić,T. Kišiček- Betonske Konstrukcije 1, Zagreb 2014

6. K. Zilch, R. Niedermeier, W. Finckh-Strengthening of Concrete Structures with Adhesively Bonded Reinforcement_ Design and Dimensioning of CFRP Laminates and Steel Plates, Wiley 2014

7. ACI Committee 440, "Guide for the Design and Construction of Externally Bonded FRP Systems for Strengthening Concrete Structures ", 440.2R-02 \& 08, American Concrete Institute, 2002.

8. Fib bulletin 14, "Externally Bonded FRP Reinforcement for RC Structures", July, 2001 